EPJ Web of Conferences 12, 03002 (2011)

DOI: $10.1051 /$ epjconf/20111203002

(C) Owned by the authors, published by EDP Sciences, 2011

\title{
Condition assessment of concrete structures at nuclear power plants by state of the art non-destructive testing
}

\author{
O. Klinghoffer ${ }^{1}$, A. Kristensen ${ }^{1}$, O. Jovall ${ }^{2}$ and N. Rydén ${ }^{3}$ \\ ${ }^{1}$ Force Technology, Park Allé 345, 2605 Brøndby, Denmark \\ ${ }^{2}$ Scanscot Technology, Edison Park, Emdalavag. 10, 22369 Lund, Sweden \\ ${ }^{3}$ Faculty of Engineering, Lund University, Box 118, 22100 Lund, Sweden
}

\begin{abstract}
The approach combining Non Destructive Examination (NDE) with Finite Element Analysis (FEA) methods is both workable and necessary in order to accurately determine and predict the condition of Nuclear Power Plant (NPP) containment structures. This approach was introduced in the European $5^{\text {th }}$ Framework Project with acronym CONMOD [1]. The current paper presents some of the work performed after the CONMOD project combining the on-site investigation at nuclear power plant (NPP) stations in Sweden and Finland. Several non-destructive techniques were chosen for the investigations described in this paper. The MASW (Multi Channel Analysis of Surface Waves) and Impact Echo (IE) techniques have been used for evaluation of thickness and stiffness of concrete and also for location of possible defects. The above-mentioned techniques have been applied under investigations of concrete containments. Additionally reinforcement corrosion was investigated in cooling water channels by means of the Galvanostatic Pulse technique allowing determination of corrosion rate. Further, following the CONMOD concept, the coupling between the non-destructive measurements on site and finite element method is established. As the result of this coupling, the information about the status of concrete structures in nuclear power plants is obtained. In the ongoing research \& development project CONSAFESYS (Concrete Containment Condition Status \& Ageing Examination System) the qualification and validation of investigative methods and diagnostic tools and analysis for reactor containments are further developed. One unique benefit with the CONSAFESYS project is the possibility of introducing artificial defects and anomalies into a decommissioned reactor containment structure.
\end{abstract}

\section{INTRODUCTION}

The main conclusion from the CONMOD project is that a new approach combining Non Destructive Examination (NDE) with Finite Element Analysis (FEA) methods is both workable and necessary in order to be able to accurately determine and predict the condition of nuclear power containment structures. CONMOD has demonstrated that other factors such as defects and unknown detailing introduced during construction can be at least and often much more critical than "classic ageing" mechanisms. This applies to critical defects introduced at the construction stage as well as conditions that can initiate and accelerate ageing processes. It has also been seen that the condition of an older containment structure is generally good and better than might be expected.

The majority of the nuclear power plants in Europe have been in operation for more than 20 years and approximately $20 \%$ for more than 30 years. Having access to effective investigation techniques and monitoring systems it will be possible to validate containment structures and thereby enable prolonged service life, e.g. from 40 to 60 years or possibly more. A consequence of this could be the avoidance of unnecessary decommissioning of plants as well as the inappropriate use of repairs and maintenance.

The resources were therefore concentrated on developing a concrete reactor containment investigation methodology that can be applied at sites in operation. The methodology was based on

This is an Open Access article distributed under the terms of the Creative Commons Attribution-Noncommercial License 3.0, which permits unrestricted use, distribution, and reproduction in any noncommercial medium, provided the original work is properly cited. 


\section{EPJ Web of Conferences}

a thorough study of the structure to be investigated, including an understanding of the construction process, and the detailing of the structure. In addition critical areas have to be identified, either highly stressed areas during accidental events, or areas with the lowest safety margins due to deterioration or defects. The testing methods to be applied and the combination of methods must be planned in detail, considering site-specific conditions. In connection to this, the feasible resolution must be achieved as well as what signal response to be awaited during the NDT measurements must be predicted.

The understanding and evaluation of the test results include extensive signal processing and numerical simulations to increase both the resolution and the accuracy of the testing results. Also, important failure modes and belonging acceptance criteria must be determined to be able to draw conclusions.

The cooling water system is also one of the most vital concrete structures in nuclear power stations and the one that is affected the most by the environment. Due to the high salinity of the cooling water, the most common damage type is reinforcement corrosion. Therefore it is important to determine when the corrosion process started and subsequently propose the most proper maintenance strategy, which is most often the installation of cathodic protection.

Extensive NDT testing has been carried out at power plants in Sweden and also in Finland on concrete reactor containment and cooling water channels. The results of these measurements are presented in the following sections of this paper.

\section{NON-DESTRUCTIVE TESTING (NDT)}

Non-destructive testing provides the means to obtain information about the structure, its components and materials [2]. With e.g. modern radiographic techniques ( $\mathrm{x}$-ray) we are able to quite easily penetrate walls up to $1.2 \mathrm{~m}$ thick to obtain information about relatively small details; to scan large surface areas using radar to map reinforcing and cable ducts; to use elegant seismic/acoustic techniques to describe the concrete structure and mechanical properties. Using MASW (Multichannel Analysis of Surface Waves) technique $[3,4]$ the concrete thickness, concrete mechanical properties and quality, and also bonding between concrete and embedded steel liner can be determined. Methods based on the electrochemical measurements-based techniques, like galvanostatic pulse technique [5], can be applied for determination of corrosion conditions, both of the containment and cooling water structures.

By combining these techniques we obtain a full and descriptive picture of the internal structure and condition of large volumes of reinforced concrete in its undisturbed state in the structure. Another advantage with the seismic-based methods is that they can all be used while the reactors are operating.

In Table 1 below is given a list of the NDT methods thought to be sufficient and suitable. Except for the HECR (high energy computed radiography), the other NDT techniques can be used with the reactor still in operation as access is only required to one side of the containment wall.

\section{NDT TESTING ON SITE}

NDT investigations of structures can be carried out at discrete points in time, as passive monitoring triggered by an event, or as measurements at predetermined intervals, if wanted almost continuously, utilising monitoring techniques. The main areas of interest when utilising monitoring and nondestructive testing are:

Actual corrosion damage in steel parts (liner, tendons, rebars and so forth), delamination of the concrete, voids or gaps in the concrete, amount of reinforcement and tendons, bond between concrete and steel parts (loss of interaction), thickness of the concrete and also detection and investigation of macro cracks in the concrete.

In the following section, the methods applied for detection of some of the above-mentioned problems are described with the obtained results and their utilisation for evaluation of ageing properties. 
Table 1. Overview of the NDT methods and their capabilities of investigating concrete in nuclear power plants.

\begin{tabular}{|c|c|c|c|}
\hline Method & Objective & Result & Comment \\
\hline GalvaPulse & $\begin{array}{l}\text { Assessment of } \\
\text { reinforcement } \\
\text { corrosion }\end{array}$ & Good & $\begin{array}{l}\text { Potential readings should } \\
\text { be supplemented by } \\
\text { corrosion current measurements }\end{array}$ \\
\hline $\begin{array}{l}\text { HECR (High } \\
\text { Energy Computed } \\
\text { Radiography) }\end{array}$ & $\begin{array}{l}\text { Reinforcement and } \\
\text { cable duct position, } \\
\text { size and condition }\end{array}$ & Good. & \\
\hline HECR & $\begin{array}{l}\text { Concrete thickness } \\
\text { (2-sided access) }\end{array}$ & Good. & Max. thickness $1400 \mathrm{~mm}$ \\
\hline Radar & $\begin{array}{l}\text { Rebar and cable duct } \\
\text { position and depth }\end{array}$ & Good. & $\begin{array}{l}\text { Max. depth } \\
\text { approx. } 400-600 \mathrm{~mm}\end{array}$ \\
\hline MASW & $\begin{array}{l}\text { Concrete thickness and } \\
\text { thickness of layers }\end{array}$ & $\begin{array}{l}\text { Good. High } \\
\text { potential. }\end{array}$ & \multirow{3}{*}{$\begin{array}{l}\text { General: Seismic response } \\
\text { should be modelled for } \\
\text { comparison. Robust method } \\
\text { not sensitive to local } \\
\text { anomalies. Provides } \\
\text { information on various wave } \\
\text { modes in wall including } \\
\text { surface and standing waves. }\end{array}$} \\
\hline MASW & $\begin{array}{l}\text { Concrete mechanical } \\
\text { properties and quality }\end{array}$ & $\begin{array}{l}\text { Good. High } \\
\text { potential. }\end{array}$ & \\
\hline MASW & $\begin{array}{l}\text { Quality of bond } \\
\text { between concrete } \\
\text { and embedded } \\
\text { steel liner }\end{array}$ & $\begin{array}{l}\text { Good. High } \\
\text { potential. }\end{array}$ & \\
\hline
\end{tabular}

\subsection{Assessment of corrosion conditions in cooling water channels}

As mentioned in the introduction, the cooling water system is one of the most vital concrete structures in nuclear power plants and the one that is affected the most by the environment. In the case of Scandinavian nuclear power plants, the water used in cooling channels is seawater with high chloride content. The high chloride content is responsible for reinforcement corrosion in the cooling water channels being the main damage problem for this part of the structure. The maintenance strategy for cooling water channels is based on determination of the time when the corrosion process is initiated and implementation of cathodic protection in order to prevent damage.

Such systems have been systematically investigated by FORCE Technology at the Barsebäck Kraft in Sweden. This power station is now closed but the cooling channels must still be investigated because they are partly functioning as foundation for the remaining buildings. During operation the cooling water channels were protected against corrosion by the cathodic protection system based on sacrificial anodes (sprayed zinc coating above the water level and massive zinc anodes below the water level).

The measurements were carried out in order to evaluate the efficiency of cathodic protection and the actual corrosion conditions of reinforcement embedded in the cooling water systems. These measurements were performed by means of the GalvaPulse equipment capable of determining corrosion potential, concrete resistance and the actual corrosion current [5]. Measurements presented below are carried out by means of connection of the working electrode of GalvaPulse equipment to the reinforcement which is in electrical contact with zinc sprayed on the concrete surface. The condition of the zinc layer has great influence on the registered potentials. The potentials are very negative in case the zinc layer is still in good condition whereas they are more positive when the zinc layer has corroded due to the protection yield for reinforcement.

The registered potentials are evaluated on the basis of ASTM C-876 Standard [6]. In addition to potentials also the concrete resistance and corrosion current of reinforcement are measured in order to obtain more data for assessment of corrosion conditions. Evaluation of corrosion current measured with GalvaPulse equipment is based on the experience obtained during many years' measurements on site 


\section{EPJ Web of Conferences}

and comparison by means of visual inspections. Based on this experience, the following criteria are proposed (table 2):

Table 2. Criteria for evaluation of corrosion conditions determined by means of GalvaPulse equipment.

\begin{tabular}{|c|c|}
\hline Corrosion current $\left[\mu \mathbf{A} / \mathbf{c m}^{2}\right]$ & Corrosion conditions \\
\hline$>15$ & High corrosion level \\
\hline $5-15$ & Moderate corrosion level \\
\hline $0.5-5$ & Low corrosion level \\
\hline$<0.5$ & Negligible corrosion level \\
\hline
\end{tabular}

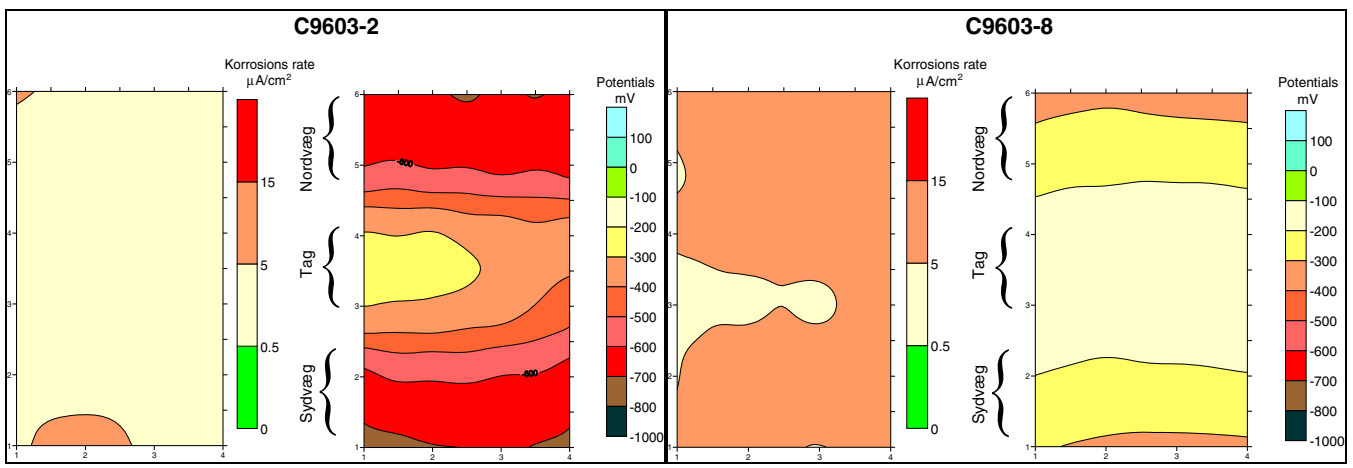

Figure 1. Influence of zinc coating on reinforcement potential. Left figure: Zinc coating is still active. Right figure: Zinc coating has been consumed.

The above specified criteria are used for evaluation of the measurements performed in the cooling water systems of Barsebäck NPP. At the same time, it must be emphasised that the presented results reflect the actual conditions at the time of measurements only, and therefore readings may be repeated in the regular interval in order to obtain the basis for the accumulated condition assessment.

How important it is to supplement potential readings with corrosion current measurements is shown in the following example from cooling water channels of Barsebäck NPP. Potential measurements are performed in two locations of cooling water structure with 30 metres' distance between them. In the first location, the applied zinc coating is still active, yielding cathodic protection to the reinforcement. In the second location, the zinc coating is consumed, and the reinforcement is no longer protected by cathodic protection. As a result of this situation, the potential registered in location with still active zinc coating is in the range of -200 to $-700 \mathrm{mV}$ vs. $\mathrm{Ag} / \mathrm{AgCl}$ reference electrode whereas in the case where zinc coating is consumed, the potentials are found between -100 to $-325 \mathrm{mV}$ vs $\mathrm{Ag} / \mathrm{AgCl}$. The obtained results are illustrated in figure 1 showing the location with intact zinc coating on the left and consumed zinc coating on the right.

The evaluation of the obtained results based on the ASTM C876 standard alone will be very difficult and require very high experience of the personal performing this job. In such cases use of corrosion current measurements make the evaluation of ongoing corrosion conditions much easier.

Measurements by means of GalvaPulse equipment have shown that the highest corrosion current was measured in the field where the zinc coating has been consumed and was therefore not able to provide cathodic protection to the reinforcement. Because zinc coating is applied for cathodic protection, the measurements of potential and corrosion current can mostly be applied for evaluation of its efficiency. 
Table 3 below summarises the most important results of measurements performed in the cooling water structures of Barsebäck NPP.

Table 3. Some results of potentials and corrosion currents measured on the cooling water structures of Barsebäck Kraft Power Station.

\begin{tabular}{|l|l|l|l|l|}
\hline Location & $\begin{array}{l}\text { Corrosion } \\
\text { current } \\
{\left[\mu \mathbf{A} / \mathbf{c m}^{2}\right]}\end{array}$ & $\begin{array}{l}\text { Potentials 2006 } \\
{[\mathbf{m V}] \mathbf{~ v s}} \\
\mathbf{A g} / \mathbf{A g C l}\end{array}$ & $\begin{array}{l}\text { Potentials 1997/1999 } \\
{[\mathbf{m V} \text { vs Ag/AgCl }]}\end{array}$ & Comments \\
\hline $\begin{array}{l}\text { Seawater } \\
\text { treatment plant }\end{array}$ & $\begin{array}{l}\text { Low } \\
\text { (moderate) }\end{array}$ & -200 till +100 & No measurements & $\begin{array}{l}\text { Low corrosion risk. } \\
\text { Coating is effective. }\end{array}$ \\
\hline $\begin{array}{l}\text { Inlet } \\
\text { structure }\end{array}$ & $\begin{array}{l}\text { Low } \\
\text { (moderate) }\end{array}$ & -900 till -300 & -750 till -350 & $\begin{array}{l}\text { No remarkable changes } \\
\text { from 1999 to 2006. }\end{array}$ \\
\hline $\begin{array}{l}\text { Secondary } \\
\text { cooling water } \\
\text { structure }\end{array}$ & Low & -815 till -335 & -350 till -325 & $\begin{array}{l}\text { Potentials in 1999 are } \\
\text { registered shortly after } \\
\text { zinc coating is applied. }\end{array}$ \\
\hline $\begin{array}{l}\text { Secondary } \\
\text { cooling water } \\
\text { structure }\end{array}$ & Low & -800 till -150 & -400 till -250 & $\begin{array}{l}\text { Potentials in 1999 are } \\
\text { registered shortly after } \\
\text { zinc coating is applied. }\end{array}$ \\
\hline $\begin{array}{l}\text { Outlet } \\
\text { structure }\end{array}$ & $\begin{array}{l}\text { Moderate } \\
\text { to Low }\end{array}$ & -850 till -425 & -900 till -800 & $\begin{array}{l}\text { Highest corrosion } \\
\text { current registered on } \\
\text { vertical direction of } \\
\text { V9516 and under roof. }\end{array}$ \\
\hline
\end{tabular}

Due to humidity changes over time and also because of different conditions of the zinc coatings, the results obtained during measurements in 2006 cannot be directly compared with results from 1996/1997. The findings from all these measurements shall be used for determination of the general corrosion state and for planning of necessary maintenance measures in order to guarantee the required service life for the cooling water structures.

\subsection{Determination of concrete mechanical properties and quality}

Methods based on seismic technology can be used for determination of concrete properties like E-modulus and thickness. In this paper the results obtained by means of a new technique called Multichannel Analysis of Spectral Waves (MASW) will be presented.

MASW is a non-destructive seismic method evaluating dynamic, linear, elastic modulus of materials. It analyses dispersion properties of certain types of seismic surface waves (Rayleigh waves and Lamb waves) propagating horizontally along the surface of measurement directly from impact point to receivers. It supplies the shear-wave velocity (Vs) or stiffness information. Data are collected with a linear array along the surface, making it possible to analyse both compression waves (P-wave), surface waves (R-wave), and Impact Echo frequencies (thickness).

The MASW equipment has been used in the selected compartments of the containment wall of a nuclear plant in Olkiluoto in Finland. The average compression wave speed $\left(\mathrm{V}_{\mathrm{P}}\right)$, shear wave speed $\left(\mathrm{V}_{\mathrm{S}}\right)$, and resonant frequency have been evaluated at each compartment. The resonant frequency has been converted to a resonant thickness in the tables below by using Lamb wave theory [7]. In this case the resonant thickness is most likely to correspond to the through thickness of the wall or the distance from the outside wall surface to the steel liner. Table 4 below shows some results of these measurements.

The evaluated average wave speeds through the concrete containment wall are quite high indicating good quality concrete. An example with raw and analysed data is shown in figure 2 . The left figure shows 
EPJ Web of Conferences

Table 4. Result from MASW Lamb Wave analysis on concrete containment wall.

\begin{tabular}{|c|c|c|c|}
\hline $\begin{array}{c}\text { Level at containment wall } \\
\text { (meters vs seawater level) }\end{array}$ & $\begin{array}{c}\text { Wave speed } \\
\text { VS [m/s] }\end{array}$ & $\begin{array}{c}\text { Resonant } \\
\text { thickness [m] }\end{array}$ & $\begin{array}{c}\text { Wave speed } \\
\text { VP [m/s] }\end{array}$ \\
\hline-2 & 2360 & 1.08 & 4415 \\
\hline-2 & 2360 & 1.08 & 4415 \\
\hline+3.5 & 2300 & - & 4303 \\
\hline+14 & 2470 & 0.85 & 4621 \\
\hline+25 & 2350 & 0.84 & 4396 \\
\hline+31.5 & 2300 & 0.86 & 4303 \\
\hline+36.5 & 2140 & - & 4004 \\
\hline
\end{tabular}
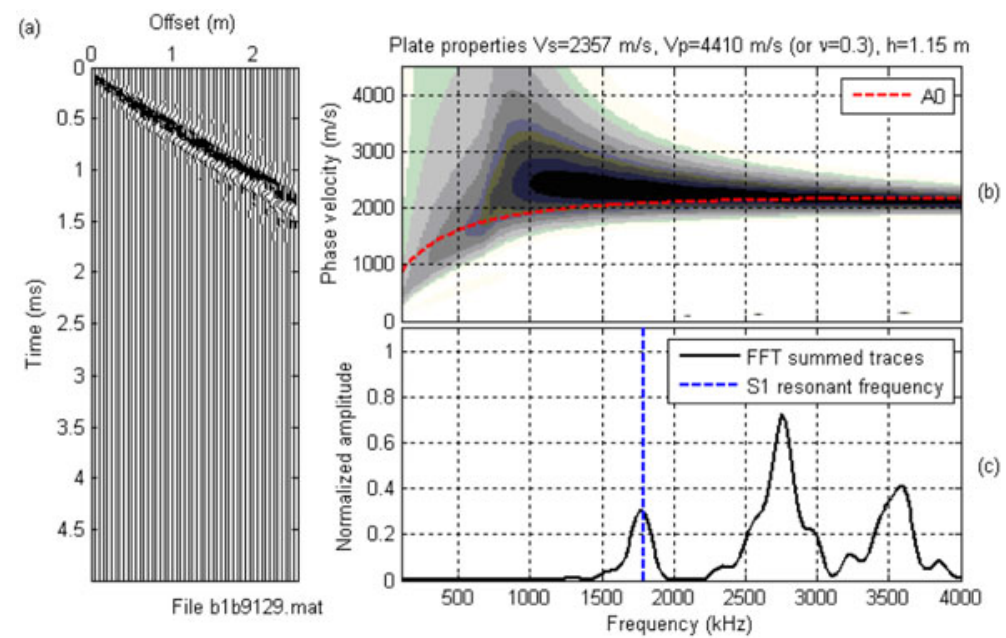

Figure 2. Example of MASW profiles from containment wall.

the recorded time signals at different distances from the source along the wall. Positive amplitudes are filled in with black. The right figure shows the corresponding phase velocity spectrum obtained from the raw data. This example indicates a homogenous concrete as there is no significant difference in velocity (stiffness) through the wall.

In the same locations as the MASW measurements were performed, cores have been drilled out to a depth up to $640 \mathrm{~mm}$ from the outside of the containment wall for the determination of concrete strength and E-modulus. Due to a dense grid of reinforcement in various depths, it was decided to reduce the diameters of cores from $100 \mathrm{~mm}$ to $80 \mathrm{~mm}$ to reduce the risk of cutting reinforcement. Before the cores were tested, the wave speed in the cores was measured using ultrasonic sound.

The obtained wave speeds can be used to calculate the dynamic E-modulus by means of the formula shown below:

$$
\mathrm{E}_{\mathrm{dyn}}=\alpha \gamma \mathrm{v}^{2} .
$$

Where: $\mathrm{E}_{\text {dyn }}$ dynamic E-modulus (GPa)

$\alpha \quad$ factor depending on Poisson's relation

$\gamma \quad$ density of concrete $\left(\mathrm{kg} / \mathrm{m}^{3}\right)$

$\mathrm{v} \quad$ wave $(\mathrm{P})$ speed in concrete $(\mathrm{m} / \mathrm{s})$

$\mathrm{P}$ Compression 


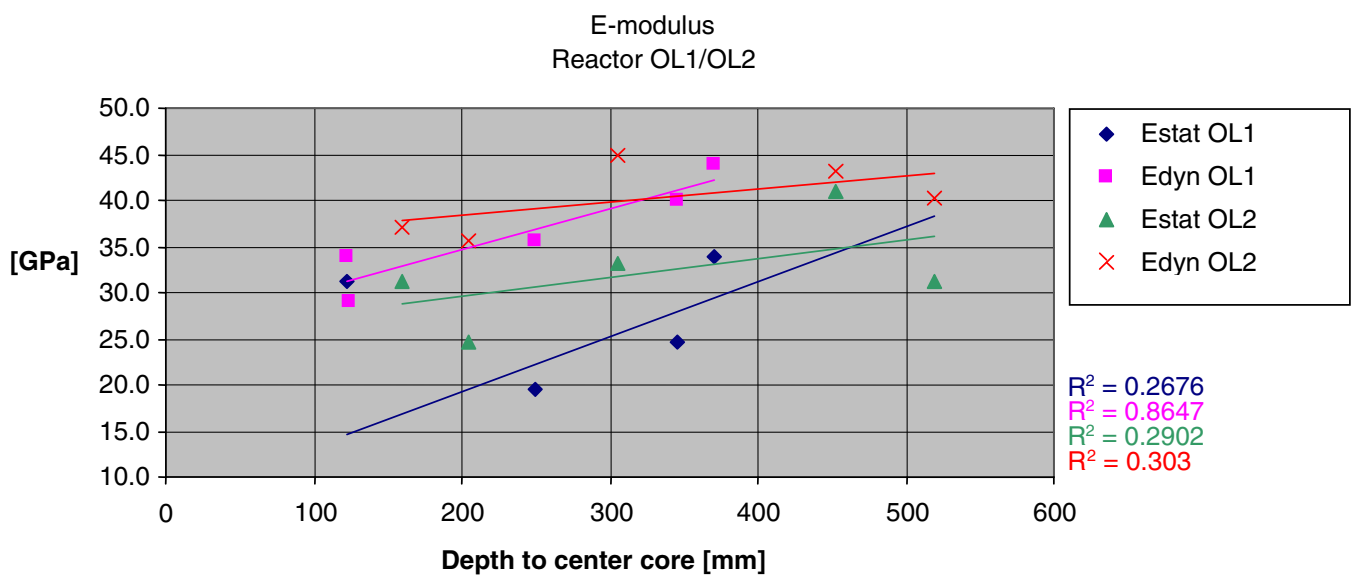

Figure 3. E-modulus measured on cores.

The factor $\alpha$ is given by

$$
\alpha=\frac{(1+v)(1-2 v)}{(1-v)} .
$$

Where $v$ is Poisson's ratio.

Table 5 gives the calculated E-modulus in GPa together with the result from the destructive test of the cores.

Table 5. Comparison between calculated E-modulus and E-modulus determined by destructive test of cores, all values are in $\mathrm{GPa}$.

\begin{tabular}{|c|c|c|c|}
\hline $\begin{array}{c}\text { Level at containment wall } \\
\text { (meters vs seawater level) }\end{array}$ & MASW & Cores NDT & Cores Test \\
\hline-2 & 32.6 & 33.9 & 31.9 \\
\hline$+3,5$ & 33.3 & - & - \\
\hline+14 & 34.7 & 32.0 & 37 \\
\hline+25 & 34.7 & - & - \\
\hline$+31,5$ & 30.6 & 28.5 & 24.8 \\
\hline$+36,5$ & 26.1 & - & - \\
\hline
\end{tabular}

In the calculations Poisson's relation is set to 0.3 which is the same as in the analysis of the MASW results. The MASW and Cores NDT columns show the calculated dynamic E-modulus, $\mathrm{E}_{\mathrm{dyn}}$, whereas the Cores Test column shows $\mathrm{E}_{\text {stat }}$ determined due to ISO 6784. The values are an average through the structure.

In figure 3, a comparison is made between E-modulus found with NDT on the cores and the destructive test of the cores. As expected, there is a clear tendency that the E-modulus is increasing with increasing depth. The coefficient of determination is a little better for the Dynamic E-modulus, which is measured by means of ultrasonic testing and therefore the eccentricity of the cores does not influence these measurements. The coefficient of determination R-squared is best when the value is at or near 1 . The R-squared is given for the trend lines below the legend. 


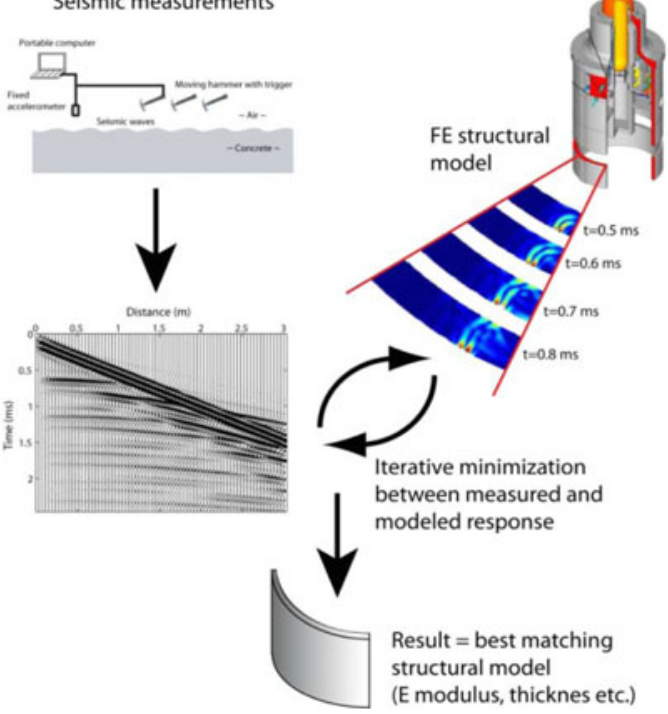

Figure 4. Schematic illustration of the proposed FE-based evaluation of measured seismic data. Figure from [9].

\section{FINITE ELEMENT (FE)-BASED EVALUATION OF MEASURED SEISMIC DATA}

The basic idea of FE-based evaluation of measured seismic data is to increase the accuracy and reliability of the results from seismic non-destructive testing of concrete containment walls. The increased accuracy and reliability is realised by using a more realistic FE model for the evaluation of the measured seismic data. 2D and 3D wave propagation simulations using FE models are in general computationally demanding. However, with the growing capabilities of modern computers and improvements in commercial FE packages, this approach has now become more realistic [8].

Figure 4 shows a schematic illustration of the proposed approach applied to NDE of concrete containment walls. Multi channel Analysis of Surface Waves (MASW) data is recorded along the surface of the wall and iteratively compared to the corresponding response from a FE model [9]. The structural properties of the FE model are changed iteratively to minimise the difference between measured and predicted seismic waves. This approach is similar to conventional inversion of seismic data [4] but improved by using a more sophisticated theoretical model.

To demonstrate some of the capabilities of FE-based models, an example is given next. The synthetic reference layer model presented in Table 5 has been used in both cases to model the cross section of the wall. This synthetic concrete containment wall is $1.0 \mathrm{~m}$ thick and has an embedded steel liner $0.734 \mathrm{~m}$ from the outer surface. The outer radius of the wall is $12.6 \mathrm{~m}$.

Table 6. Layering and material properties used in the reference model.

\begin{tabular}{|l|c|c|c|c|c|c|}
\hline Medium & $\begin{array}{c}\text { Thickness } \\
(\mathbf{m m})\end{array}$ & E-modulus (GPa) & $V_{\boldsymbol{P}}(\mathbf{m} / \mathbf{s})$ & $V_{\boldsymbol{S}}(\mathbf{m} / \mathbf{s})$ & $v$ & $\begin{array}{c}\text { Density } \\
\mathbf{( k g / m 3})\end{array}$ \\
\hline Air (outside) & & & & & & \\
\hline Concrete & 734 & 33.621 & 3945 & 2416 & 0.20 & 2400 \\
\hline Steel & 6 & 200 & 6144 & 3095 & 0.33 & 7850 \\
\hline Concrete & 260 & 33.621 & 3945 & 2416 & 0.20 & 2400 \\
\hline Air (inside) & & & & & & \\
\hline
\end{tabular}




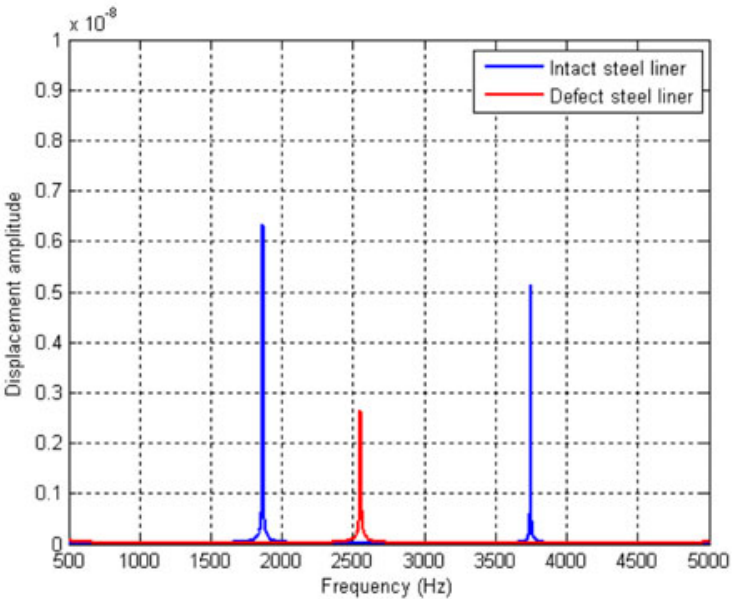

(a)
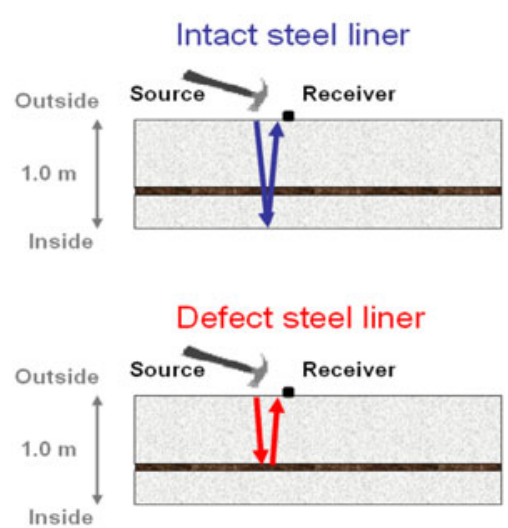

(b)

Figure 5. FE simulation of an impact echo test over an intact steel liner (blue) and a defect steel liner (red). The test is simulated from the "outside" of the reference layer model (Table 3.2) and predicts the fundamental resonance frequencies to be $1865 \mathrm{~Hz}$ and $2550 \mathrm{~Hz}$ for intact and defect conditions, respectively. The second blue peak at 3750 is the first higher mode resonance for the intact wall. Figure from [10].

In this example, FE modeling is used to predict a theoretical defect in the 6-mm thick steel liner (steel layer in Table 3.2). Figure 5(a) shows the amplitude spectrum from a FE simulation of the impact echo test [8] over the delaminated area. The blue line in Figure 5(b) shows the theoretical spectrum from an intact liner, and the red curve shows the spectrum from a defect liner. In this example, the defected liner is modeled as a drop in E-modulus (to $10 \mathrm{MPa}$ ) comparable to a severely corroded steel liner. The echo from the defect liner is clearly visible at $2550 \mathrm{~Hz}$, and there is now no echo from the back wall.

\section{CONCLUSIONS}

The corrosion measurements performed by means of GalvaPulse equipment on the cooling water systems of Barsebäck NPP Power Plant show that potential readings should be supplemented by determination of corrosion current, which makes the condition assessment more unambiguous and thus also easier.

These measurements were also useful for evaluation of the efficiency of the applied cathodic protection which is a very important maintenance measure to ensure the required service life of the cooling water systems. Thus these measurements are important contributions when evaluating ageing of concrete in nuclear power plants, which was the aim of two research projects referred to in this paper.

The same measurements as described above for cooling water systems can be applied for evaluation of corrosion in the concrete containment of nuclear power plants.

The results of investigations by means of seismic methods show that there is a good coherence between the findings of the non-destructive testing and the laboratory test of the drilled out cores. The laboratory tests carried out on the concrete cores confirmed the MASW data, and showed a quite clear trend that the strength of the concrete was increasing with increasing depth.

The thicknesses measured to the steel liner and to the back wall with the different seismic methods correlated reasonably with the expected depth of $1.1 \mathrm{~m}$ to the back wall and $0.95 \mathrm{~m}$ to the steel liner.

The MASW technique provides valuable information about the condition of the containment wall with regard to thickness and velocity profile which can be used to estimate the E-modulus. 
For future research and development of NDE techniques for concrete containment walls, it is important to move towards more realistic $2 \mathrm{D}$ and $3 \mathrm{D}$ theoretical models. It can be argued that the true potential of seismic wave-based techniques has not been fully explored due to the simplified theoretical models used for the evaluation of measured data. The complete seismic wave field recorded along the surface of a structure includes a lot of information about the structural properties of the medium. To fully utilise this measured information, sophisticated 2D and 3D full waveform models need to be utilised for the evaluation of seismic measurements.

Numerical simulations can be used to determine critical areas of the containment most vulnerable to defects and ageing mechanisms. Also, the effect of detected defects or degradation processes on the stress and strain state of the containment can be determined by numerical simulation, as a way of understanding the impact on the containment leak-tightness and load-bearing capacity. If the rate of ageing is known, simulations can be used to determine critical points in time when countermeasures must be taken to ensure operational or safety functions of the containment.

Numerical models of the structure to be investigated are used to predict measurement responses for an undamaged structure and for a structure with defects; also the size of the defect may be varied to estimate how small defects are possible to identify by the measurement method. When the measurements are finalised, the digital mock-ups can be used in a similar way to more clearly understand and interpret the measurement data.

\section{References}

[1] Joint report by FORCE Technology, Scanscot Technology and Barsebäck NPP - CONMOD Main Report, European 5-th Framework Project (2005).

[2] Malhotra, V.M., and Carino, N.J., Handbook on nondestructive testing of concrete, $2^{\text {nd }}$ edition, CRC Press LLC, New York, ISBN 0-8031-2099-0 (2004).

[3] Park, C.B., Miller, R.D., and Xia, J., “Multichannel analysis of surface waves”, Geophysics, Vol. 64(3), pp 800-808 (1999).

[4] Ryden, N., and Park, C.B., Fast Simulated Annealing Inversion of Surface Waves on Pavements using Phase Velocity Spectra, Geophysics, Vol. 71, No. 4, pp R49-R58 (2006).

[5] Elsener B., Klinghoffer O., Frølund T., Rislund E., Schiegg Y. and Böhni H.,: Assessment of Reinforcement Corrosion by Galvanostatic Pulse Technique, Proc. Int. Conf. on Repair of Concrete Structures, Svolvaer, Norway, pp 391 - 400 (1997).

[6] American Society of Testing and Materials: Standard Test Method for Half-Cell Potentials of uncoated Reinforcing Steel in Concrete, ASTM C876 (1987).

[7] Gibson, A., and Popovics, J., Lamb wave basis for impact-echo method analysis, Journal of Engineering Mechanics, ASCE, Vol. 131, No. 4, pp 438-443 (2005).

[8] Romano, A. J., Bucaroa, J. A., and Deyb, S., Defect detection and localization in orthotropic wood slabs by inversion of dynamic surface displacements, J. Acoust. Soc. Am. Vol. 124 No. 2, pp 918-925 (2008).

[9] Sansalone, M., and Streett, W., Impact-Echo Nondestructive Evaluation of Concrete and Masonry. Ithaca, NY: Bullbrier Press (1997).

[10] Ryden, N., Jovall, O., Kristensen, A., Finite element based evaluation of seismic non-destructive tests on concrete containment walls, Proceedings of the Nuclear Energy Agency (NEA) workshop on Ageing management of thick-walled concrete structures, including in-service inspections maintenance and repair, instrumentation methods and safety assessment in view of long-term operation, Prague, Czech Republic (1-3 October 2008). 